\begin{tabular}{|c|c|}
\hline Title & Cryopreservation diluents for spermatozoa of Sakhalin taimen Hucho perryi \\
\hline Author(s) & $\begin{array}{l}\text { Kusuda, Satoshi; Koide, Nobuhisa; Kawamula, Hiloshi; Teranishi, Tetsuo; Nakajima, Jun-ichiro; Y amaha, Etsuro; A rai, } \\
\text { Katsutoshi; Ohta, Hiromi }\end{array}$ \\
\hline Citation & $\begin{array}{l}\text { Fisheries Science, 71(2), 293-298 } \\
\text { https://doi.org/10.1111/.1444.2906.2005.00963.x }\end{array}$ \\
\hline Issue Date & 2005 \\
\hline DOC URL & http:/hdl.handle.net $/ 2115 / 35212$ \\
\hline Rights & ○ 2005 公益社団法人日本水産学会; ○ 2005 The Japanese Society of Fisheries Science \\
\hline Type & article \\
\hline File Information & arai-102.pdf \\
\hline
\end{tabular}

Instructions for use 


\title{
Cryopreservation diluents for spermatozoa of Sakhalin taimen Hucho perryi
}

\author{
Satoshi KUSUdA,,${ }^{1,2 *}$ Nobuhisa KOIDE, ${ }^{1}$ Hiloshi KaWAMUla, ${ }^{1}$ Tetsuo TERANISHI, ${ }^{1}$ \\ Jun-ICHIRo NAKAJIMA, ${ }^{2}$ ETsuro YAMAHA, ${ }^{3}$ KaTsutoshi ARAI ${ }^{2}$ AND Hiromi OHTA ${ }^{4}$
}

\begin{abstract}
${ }^{1}$ Hokkaido Fish Hatchery, Eniwa, Hokkaido 061-1433, ${ }^{2}$ Graduate School of Fisheries Sciences, Hokkaido University, Hakodate, Hokkaido 041-8611, ${ }^{3}$ Nanae Fresh-Water Laboratory, Field Science Center for Northern Biosphere, Hokkaido University, Nanae, Hokkaido 041-1105 and ${ }^{4}$ Laboratory of Aquaculture, Department of Fisheries, Faculty of Agriculture, Kinki University, Nara 631-8505, Japan
\end{abstract}

\begin{abstract}
To develop a suitable cryopreservation diluent for spermatozoa of the endangered Sakhalin taimen Hucho perryi, all possible combinations of cryoprotectants (glycerol, dimethyl sulfoxide [DMSO], methanol) and extenders (fetal bovine serum [FBS], $300 \mathrm{mM}$ glucose solution [GS], artificial seminal plasma for masu salmon) were examined by observing sperm motility $10 \mathrm{~s}$ after thawing. Spermatozoa cryopreserved with diluents such as mixtures of $10 \%$ glycerol plus $90 \%$ FBS, $10 \%$ DMSO plus $90 \%$ FBS, and $10 \%$ methanol plus $90 \%$ GS showed the highest motility. The maximal post-thaw motility was observed at $10 \%$ among all concentrations $(0,5,10,15$ and $20 \%)$ of these three cryoprotectants. No significant difference among three diluents was observed in motility at $10 \mathrm{~s}$. Mixtures of $10 \%$ glycerol plus $90 \%$ FBS, $10 \%$ DMSO plus $90 \%$ FBS, and $10 \%$ methanol plus $90 \%$ GS are suitable cryopreservation diluents for Sakhalin taimen spermatozoa.
\end{abstract}

KEY WORDS: cryopreservation, cryoprotectant, extender, Hucho perryi, Sakhalin taimen, spermatozoa.

\section{INTRODUCTION}

The Sakhalin taimen Hucho perryi is only distributed in Sakhalin Island, the southern Kurile Islands, the Primorye region of Siberia, and the northernmost island of Japan, Hokkaido. ${ }^{1}$ The species is iteroparous and reproducible up to about 16 years of age ${ }^{2}$ and is the largest salmonid in the western Pacific Ocean, attaining weights up to 25$60 \mathrm{~kg}{ }^{3,4}$ They are partly anadromous. ${ }^{5}$ However, even the anadromous form is often land-locked by artificial dams and obliged to spend the nonbreeding period in freshwater lakes. Especially in Hokkaido, they are now very rare, seriously endangered and close to extinction. ${ }^{6}$ Therefore, adequate management and conservation of this species is very important.

In teleosts, since cryopreservation is an effective method for gene-banking endangered species, the development of appropriate techniques for sperm cryopreservation is essential. Sperm has been successfully cryopreserved in a relatively large number of fish species, ${ }^{7}$ including salmonid species. ${ }^{8}$

*Corresponding author: Tel: 81-123-32-2135.

Fax: 81-123-34-7233. Email: kusudas@fishexp.pref.hokkaido.jp Received 20 May 2004. Accepted 6 October 2004.
Recent advances in chromosome manipulation to induce androgenetic diploid genotypes have made it possible to generate individuals from cryopreserved sperm. Bercsényi et al. ${ }^{9}$ have successfully achieved interspecific androgenesis using genetically-inactivated eggs of one species and normal sperm of another in cyprinids. Gamma ray-irradiated eggs of common carp Cyprinus carpio were fertilized with cryopreserved sperm of goldfish Carassius auratus and the androgenetic haploid embryos were then heat-shocked to restore diploidy and to produce viable offspring. Babiak et al. ${ }^{10}$ have also produced viable diploids in androgenetic rainbow trout Oncorhynchus mykiss by using cryopreserved sperm. Therefore, sperm cryopreservation is the first step for regeneration of endangered species. Successful sperm cryopreservation has been reported in Danube salmon Hucho hucho ${ }^{11,12}$ which is distributed in Eurasia. In the Sakhalin taimen, the optimum diluent for sperm cryopreservation has not been systematically investigated in terms of the combination of cryoprotectant and extender, nor has cryopreservation yet been attempted. The present study was conducted to develop a suitable cryopreservation diluent for Sakhalin taimen spermatozoa. We examined the effects of the combination of cryoprotectant and extender, and those of a concentra- 
tion of cryoprotectant on the post-thaw motility of Sakhalin taimen spermatozoa.

\section{MATERIALS AND METHODS}

\section{Collection of gametes}

Twenty-two 7-year-old males of Sakhalin taimen were used in this study. They were raised in outdoor ponds under natural light conditions until the time of final maturation at Ibeshibetsu hatchery of the Akan Fisheries Cooperative Association (Akan, Hokkaido). At the time of collection the fish were anesthetized with 2-phenoxyethanol in order to allow more complete control during the collection process. Ripe males were wiped with a damp towel to avoid contamination of the milt with water and mucus. Semen was collected in a Petri dish by gently pressing the abdomen of the fishes. When the amount of expressible semen from one male was very little, those from up to three males were pooled and used as a single sample. In order to evaluate motility of fresh sperm, semen from each sample was diluted 1:1000 with a $120-\mathrm{mM} \mathrm{NaHCO}_{3}$ solution (thawing solution), ${ }^{13}$ and then sperm motility was assessed $10 \mathrm{~s}$ after dilution by modified grades that were decided by Ohta et al. ${ }^{14}$ Samples with percentages of cells with progressive motility under $50 \%$ were discarded. The percentage of motile spermatozoa ranged from approximately half to three-quarters of spermatozoa in six samples, whereas more than three-quarters of spermatozoa in another five samples. Sperm concentration was determined by mixing $1 \mu \mathrm{L}$ of semen with $1 \mathrm{~mL}$ of artificial seminal plasma (ASP) for masu salmon. ${ }^{15}$ Cell counts were performed using a hemocytometer chamber (Thoma). The sperm concentration of the semen for experiments ranged from $2.9 \times 10^{9}$ cells $/ \mathrm{mL}$ to $11.6 \times 10^{9}$ cells/ $\mathrm{mL}$ in 11 samples and the average was $8.1 \pm 0.6 \times 10^{9} \mathrm{cells} / \mathrm{mL}$. Semen was kept in a Petri dish placed on crushed ice and used for experiments within $4 \mathrm{~h}$.

\section{Freezing and thawing}

Cooling of semen was carried out at Ibeshibetsu hatchery by the pellet method. Fresh semen was diluted six times with diluent containing cryoprotectant and extender. A total of $100 \mu \mathrm{L}$ of the diluted semen was dropped within $1 \mathrm{~min}$ after dilution on a small depression, about $5 \mathrm{~mm}$ in diameter and $3 \mathrm{~mm}$ depth, of dry ice $\left(-79^{\circ} \mathrm{C}\right)$. After $5 \mathrm{~min}$, frozen pellets were immersed in liquid nitrogen $\left(-196^{\circ} \mathrm{C}\right)$, transferred to the laboratory of
Hokkaido Fish Hatchery (Eniwa, Hokkaido), and cryopreserved for more than 19 days.

One pellet was taken from the container of liquid nitrogen with pre-cooled tweezers, immersed in $5 \mathrm{~mL}$ of a thawing solution ${ }^{13}$ at $25^{\circ} \mathrm{C}$, mixed for 1 or $2 \mathrm{~s}$ on a vortex mixer and then thawed. The pellet melted away within about $7 \mathrm{~s}$.

Using this procedure, the post-thaw motility was examined under the following various parameters: (i) cryoprotectant (glycerol, dimethyl sulfoxide [DMSO], methanol); (ii) concentration of these cryoprotectants $(0,5,10,15$ and $20 \%)$; and (iii) extender (fetal bovine serum [FBS], ASP, $300 \mathrm{mM}$ glucose solution [GS]).

\section{Evaluation of sperm motility}

To estimate the post-thaw motility of cryopreserved sperm, an aliquot of the activated sperm was transferred immediately onto a glass slide, and motility was observed without a cover slip. The motility was recorded with a VHS video-recorder (model A-J1; Toshiba Co., Tokyo, Japan) and video camera (model KP-C251, Hitachi Electronics Engineering Co. Ltd., Tokyo, Japan) connected to a microscope (Microphot-FX; Nikon Co, Tokyo, Japan) system (an object lens of $\times 20$ ). The video recording was started simultaneously with the loss of the pellet's shape in thawing solution. Motility was observed $10 \mathrm{~s}$ after thawing.

Spermatozoa were considered motile when the sperm head showed forward movement under the consecutive video frames from $10 \mathrm{~s}$ after thawing. Percent motility was determined by assessing the motility of at least 50 randomly selected spermatozoa for each measurement. Measurements at each dilution were repeated twice using two pellets, and the average result was used in the data analysis.

\section{Statistical analyses}

All data are represented as mean \pm standard error of the mean (SE). Percent motilities were transformed by angular transformation and analyzed statistically using ANOVA and the Tukey test (Honestly significant difference test). ${ }^{16}$ A value of $P<0.05$ was considered to represent statistical significance.

\section{RESULTS}

\section{Cryoprotectant and extender}

The effects of all possible combinations of various $10 \%$ cryoprotectants and $90 \%$ extenders in the 
Fig. 1 Post-thaw motility of spermatozoa cooled with $10 \%$ cryoprotectants and $90 \%$ extenders, or cooled with $100 \%$ extenders. (a) glycerol, (b) DMSO, (c) methanol, (d) extender alone. Values represent the mean \pm SE for milt from six samples. Within each graph, means with different letters are significantly different $(P<0.05)$.



diluent on motility $10 \mathrm{~s}$ after thawing were examined (Fig. 1). In the case of glycerol, cryopreserved sperm showed the high post-thaw percent motility in each extender, especially highest in FBS (Fig. 1a). When DMSO was diluted with FBS, cryopreserved sperm in this diluent showed a significantly higher percent motility than ones with other extenders (Fig. 1b); while sperm cryopreserved with the diluent consisting of methanol and GS showed the highest percent motility among those with other extenders (Fig. 1c). When the diluent lacked cryoprotectant, cryopreserved sperm in GS showed the highest post-thaw percent motility of all the extenders examined (Fig. 1d). A higher postthaw percent motility was also obtained in FBS than in ASP. The optimum combination between cryoprotectants and extenders was determined in this experiment, that is, glycerol plus FBS, DMSO plus FBS, and methanol plus GS.

The effects of the concentration of three cryoprotectants (glycerol, DMSO and methanol) in these diluents were examined by observing the motility $10 \mathrm{~s}$ after thawing (Fig. 2). In the case of glycerol (Fig. 2a), although no significant difference between different concentrations in the range of 5$20 \%$ glycerol was observed in terms of the percent motility, the percentages of motile spermatozoa increased with the increasing glycerol concentration, were the highest at $10 \%$, and decreased with more than $15 \%$. In the case of DMSO and methanol (Fig. 2b,c), the percent motility showed a similar tendency and was also the maximal at $10 \%$ of all concentrations of them examined.

\section{Comparison of motility between present diluents and other}

When sperm was cooled in the above-mentioned three diluents ( $10 \%$ glycerol plus $90 \%$ FBS, $10 \%$ DMSO plus $90 \%$ FBS, and $10 \%$ methanol plus $90 \%$ GS) and diluent containing 10\% DMSO and $90 \%$ $\mathrm{GS}^{13}$ that has been widely used in sperm cryopreservation of salmonid fish, no significant difference among these three diluents was observed in motility $10 \mathrm{~s}$ after thawing; however, they showed significantly higher percent motility than that of the diluent consisting of $10 \%$ DMSO and $90 \%$ GS (Fig. 3).

\section{DISCUSSION}

The goal of this study was to develop a suitable cryopreservation diluent for Sakhalin taimen spermatozoa. Since the pellet method has been widely used in a relatively large number of laboratories and salmon hatcheries because of its favorable post-thaw fertility and its simplicity, ${ }^{17}$ it was carried out in this study. Fertilization tests were difficult in the Sakhalin taimen because a large number of eggs were required for these experiments. Postthaw motility was chosen as the criterion to determine a suitable cryopreservation diluent.

In the present study, the results of sperm motility $10 \mathrm{~s}$ after thawing suggest that $10 \%$ glycerol in FBS, $10 \%$ DMSO in FBS, and $10 \%$ methanol in GS are the optimum diluents. Lahnsteiner et al. ${ }^{11}$ demon- 


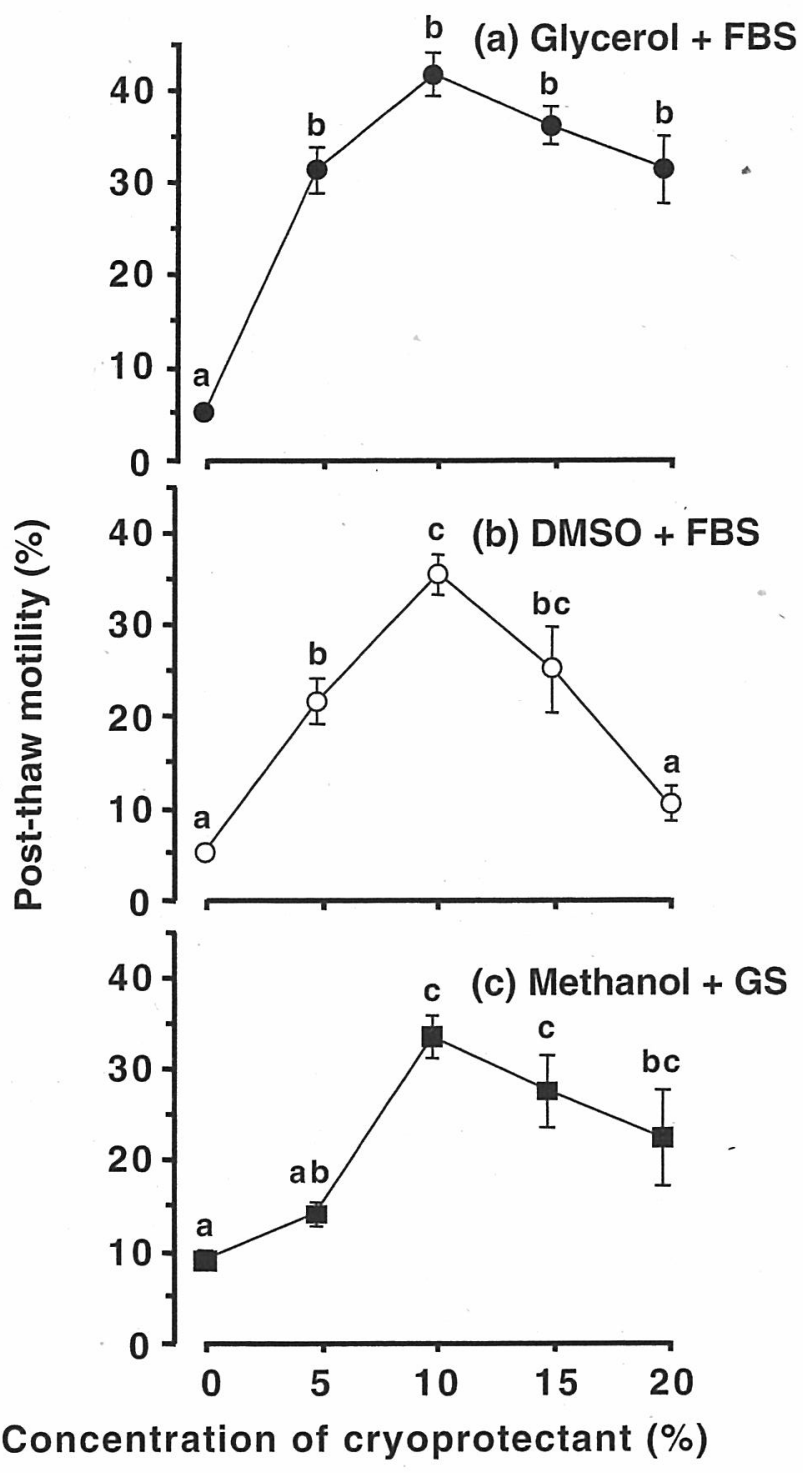

Fig. 2 Post-thaw motility of spermatozoa cooled with three diluents containing $0-20 \%$ each cryoprotectant. (a) glycerol + FBS, (b) DMSO + FBS, (c) methanol + GS. Values represent the mean $\pm \mathrm{SE}$ for milt from five samples. Within each graph, means with different letters are significantly different $(P<0.05)$.

strated the successful cryopreservation of the Danube salmon spermatozoa using diluent containing $10 \%$ methanol as permeating cryoprotectant and 90\% extender $(103 \mathrm{mM} \mathrm{NaCl}$, $40 \mathrm{mM} \mathrm{KCl}, 1 \mathrm{mM} \mathrm{CaCl} 2,0.8 \mathrm{mM} \mathrm{MgSO}_{4}, 20 \mathrm{mM}$ HEPES [pH 7.8], $1.5 \%$ bovine serum albumin, $7 \%$ egg yolk, $0.5 \%$ sucrose) by the straw method. Glogowski et al. ${ }^{12}$ also showed that the diluents containing $10 \%$ DMSO, $300 \mathrm{mM}$ glucose, $25 \mathrm{mM}$ $\mathrm{KCl}$, and $10 \%$ yolk or that containing $20 \%$ glycerol, $300 \mathrm{mM}$ glucose, and $10 \%$ yolk, were the most

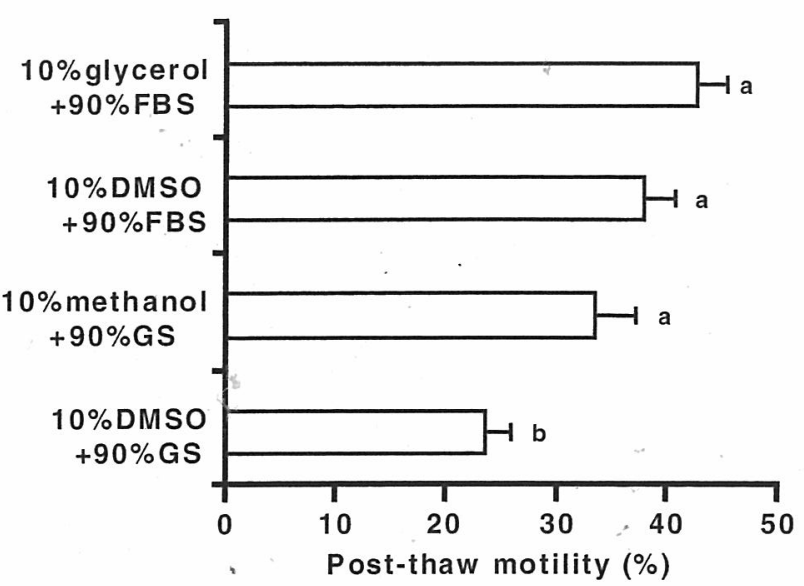

Fig. 3 Post-thaw motility of spermatozoa cooled with four diluents $10 \mathrm{~s}$ after thawing. Values represent the mean \pm SE for milt from six samples. Means with different letters are significantly different $(P<0.05)$.

suitable for the cryopreservation of the Danube salmon spermatozoa by the pellet method. They obtained $70-90 \%$ eyed stage embryos after fertilization with cryopreserved spermatozoa as compared to the control fertilization rate. Thus, methanol, DMSO and glycerol are likely to be effective cryoprotectants for spermatozoa in Danube salmon. This is consistent with the results of the present study. On the other hand, although glycerol has been known to be inadequate as cryoprotectant of other salmonids ${ }^{18-20}$ and striped bass Morone saxatilis sperm ${ }^{21}$ because of the resultant low fertility, the diluent with glycerol in this study gave high post-thaw motility. The discrepancy between the present result and the previous studies $^{18-21}$ is not clear at present. Glycerol may cause lower fertility after insemination. Further studies, especially fertilization experiments, will be required.

In this study, the optimum concentration of cryoprotectants was $10 \%$. It was the same as that in previous studies of Danube salmon, ${ }^{11,12}$ and was covered within limits of the partial concentrations of cryoprotectants (5-20\%), ${ }^{7}$ at which cryoprotectants displayed the beneficial effect of cryoprotection on cryopreserved sperm. The concentration (5-20\%) of glycerol did not affect post-thaw motility; whereas the limits of effective concentration of DMSO and methanol, allowing better post-thaw motility to be achieved, were smaller than that of glycerol. These results might be caused by the nature (for example, molecular weight) of cryoprotectants examined. Harvey ${ }^{22}$ reported that cryoprotection was maximal when $5 \%$ methanol plus $15 \%$ powdered milk as intracellular and extracellular cryoprotectants were used 
for cryopreservation of Tilapia Sarotherodon mossambicus spermatozoa, and either cryoprotectant alone provided lower protection ability than their combination. Therefore, the limits of the protecting effect of methanol could be improved by adding extracellular cryoprotectants in the present diluents.

These three diluents recommended in this study gave a significantly higher motility than that of a mixture of $10 \%$ DMSO and $90 \%$ GS. Therefore, they were considered to be suitable cryopreservation diluents for the Sakhalin taimen spermatozoa and would be available as the cryopreservation diluents for sperm in other salmonids. Since fertilization tests could not be conducted in this study, the relationship between motility and fertility remains unclear. It is known that the post-thaw fertility and percent motility of cryopreserved spermatozoa were positively correlated in rainbow trout, ${ }^{8}$ amago salmon Oncorhynchus masou ishikawae, ${ }^{23}$ northern pike Esox lucius ${ }^{24}$ and zebrafish Brachydanio rerio. ${ }^{25}$ When the effects of GS containing $10 \%$ methanol or $10 \%$ DMSO were examined on the post-thaw fertility in a preliminary experiment, cryopreserved spermatozoa in the Sakhalin taimen showed a significantly higher fertility in the former $(82.0 \pm 0.9 \%)$ than in the latter $(45.1 \pm 2.2 \%) .{ }^{26}$ Thus, the effect of methanol on post-thaw motility is likely linked up with its fertility. Further investigation should be conducted to clarify the relationship between motility and fertility of cryopreserved spermatozoa in the Sakhalin taimen as well as to decide the best diluent.

In conclusion, this study indicated that mixtures of $10 \%$ glycerol plus $90 \%$ FBS, $10 \%$ DMSO plus $90 \%$ FBS, and $10 \%$ methanol plus $90 \%$ GS would be suitable as the cryopreservation diluent for Sakhalin taimen spermatozoa.

\section{ACKNOWLEDGMENTS}

We wish to thank Mr Shizuo Kimura, Nanae Fresh Water Laboratory, Field Science Center for Northern Biosphere, Hokkaido University, and the staff of the Akan Fisheries Cooperative Association for their support. We also wish to thank Mrs Yukie Hujimoto and the staff of Hokkaido Fish Hatchery for their support. This study was supported in part by grants from Japanese Fisheries Resource Conservation Association.

\section{REFERENCES}

1. Kimura S. On the life history of the salmonid fish, Hucho perryi (Brevoort), found in Nemuro, Hokkaido. Jpn. J. Ichthyol. 1966; 14: 17-25 (in Japanese with English summary).
2. Gritsenko OF, Malkin EM, Churikov AA. Sakhalinskii taimen' Hucho perryi (Brevoort) reki Bogatoi (vostochnoe poberezh'e Sakhalin). Izvestiya TINRO 1974; 93: 91-100 (in Russian).

3. $₫$ Berg LS. Freshwater Fishes of the U.S.S.R. and Adjacent Countries, Vol. 1. The Israel Program for Scientific Translations Press, Jerusalem, 1962.

4. Khatkevich V. Chevitsa-perspektivnyi ob'ekt lososevodstva. Rybovodstvo i Rybovodstvo 1973; 1: 19 (in Russian).

5. Kawamula H, Mabuchi M, Yonekawa T. The Japanese huchen, Hucho perryi (Brevoort), collected in brackish water Lake Akkeshi, eastern Hokkaido, Japan. Sci. Rep. Hokkaido Fish Hatchery 1983; 38: 47-55 (in Japanese with English abstract).

6. Japanese Environment Agency. Red List for Brackish and Freshwater Fishes in Japan. 'Government of Japan, Tokyo, 1999 (in Japanese).

7. Leung LK, Jamieson BG. Live preservation of fish gametes. In: Jamieson BG (ed). Fish Evolution and Systematics: Evidence from Spermatozoa. Cambridge University Press, Cambridge. 1991; 245-269.

8. Lahnsteiner F. Semen cryopreservation in the salmonidae and in the northern pike. Aquacult. Res. 2000; 31: 245-258.

9. Bercsényi M, Magyary I, Urbányi B, Orbán L, Horváth L. Hatching out goldfish from common carp eggs: interspecific androgenesis between two cyprinid species. Genome 1998; 41: 573-579.

10. Babiak I, Dobosz S, Goryczko K, Kuzminski H, Brzuzan P, Ciesielski S. Androgenesis in rainbow trout using cryopreserved spermatozoa: the effect of processing and biological factor. Theriogenology 2002; 57: 1229-1249.

11. Lahnsteiner F, Weismann T, Patzner R. Cryopreservation of semen of the grayling (Thymallus thymallus) and the Danube salmon (Hucho hucho). Aquaculture 1996; 144: 265-274.

12. Glogowski J, Babiak I, Goryczko K, Dobosz S, KuŸmiñski H. Properties and cryopreservation of Danube salmon (Hucho hucho) milt. Arch. Pol. Fish. 1997; 5: 235-239.

13. Stoss J, Refstie T. Short-term storage and cryopreservation of milt from Atlantic salmon and sea trout. Aquaculture 1983; 30: 229-236.

14. Ohta H, Kusuda S, Kudo S. Motility of testicular spermatozoa in shishamo smelt Spirinchus lanceolatus. Nippon Suisan Gakkaishi 1995; 61: 7-12 (in Japanese with English abstract).

15. Ohta $H$, Unuma T, Nagoya H. Diluents for cool storage of milt and for artificial fertilization in the amago salmon Oncorhynchus masou ishikawae. Nippon Suisan Gakkaishi 2000; 66: 88-96 (in Japanese with English abstract).

16. Zar JH. Biostatistical Analysis, 4th edn. Prentice Hall, New Jersey, 1999.

17. Stoss J. Fish gamete preservation and spermatozoan physiology. In: Hoar WS, Randall DJ, Donaldson EM (eds). Fish Physiology, Vol. 9B. Academic Press, New York. 1983; 305350.

18. Scott AP, Baynes SM. A review of the biology, handling and storage of salmonid spermatozoa. J. Fish Biol. 1980; 17: 707739.

19. Erdahl AW, Erdahl DA, Graham EF. Some factors affecting the preservation of salmonid spermatozoa. Aquaculture 1984; 43: 341-350. 
20. Holtz W. Cryopreservation of rainbow trout (Oncorhynchus mykiss) sperm: practical recommendations. Aquaculture 1993; 110: 97-100.

21. Kerby JH. Cryogenic preservation of sperm from Striped Bass. Trans. Am. Fish Soc. 1983; 112: 86-94.

22. Harvey B. Cryopreservation of Sarotherodon mossambicus spermatozoa. Aquaculture 1983; 32: 313-320.

23. Ohta $\mathrm{H}$, Shimma $\mathrm{H}$, Hirose K. Relationship between fertility and motility of cryopreserved spermatozoa of the amago salmon Oncorhynchus masou ishikawae. Fish. Sci. 1995; 61: 886-887.
24. Babiak I, Glogowski J, Luczynski MJ, Kucharczyk D, Luczynski M. Cryopreservation of the milt of the northern pike. J. Fish Biol. 1995; 46: 819-828.

25. Harvey B, Kelley RN, Ashwood-Smith MJ. Cryopreservation of zebra fish spermatozoa using methanol. Can. J. Zool. 1982; 60: 1867-1870.

26. Kusuda S, Koide N, Kawamula H, Teranishi T, Yamaha E, Arai K. Cryopreservation of Sakhalin taimen Hucho perryi spermatozoa: effect of cryoprotectants on post-thaw fertility. Suisanzoshoku 2004; 52: 171-175. 